\title{
Climate Zone Classification of India Using New Base Temperature
}

\author{
Mayank Bhatnagar ${ }^{1}$, Jyotirmay Mathur ${ }^{1}$, Vishal Garg ${ }^{2}$ \\ ${ }^{1}$ Malaviya National Institute of Technology, Jaipur, India \\ ${ }^{2}$ International Institute of Information Technology, Hyderabad, India
}

\begin{abstract}
The development of building codes for energy efficiency depends on climate zones. National Building Codes of India prescribes five climate zones in India. This classification does not consider fluctuations of outdoor conditions and its effect on indoor comfort conditions. The indoor comfort conditions can be incorporated by using Heating Degree Day (HDD) and Cooling Degree Day (CDD) analysis. Additionally, this classification used mean monthly temperature which cannot capture extreme conditions of the month while the degree day can account for fluctuations in the outdoor temperature and eliminate those periods when heating or cooling systems do not need to operate for a day.

This study proposes a new climate zones classification based on hierarchical cluster analysis on 60 Indian locations. The analysis uses climate indices such as HDD, CDD and annual mean relative humidity as variables for clustering analysis. The 60 locations are grouped into 8 climate zones. Three climate zones have only one city as they are distinct from the other location in terms of climate. This updated climate classification may improve the accuracy of the energy conservation codes and building design.
\end{abstract}

\section{Introduction}

The weather of an area represents the state of the atmospheric environment over a brief period. Integrated weather condition over 30 years is generally referred to as climate or more accurately, as macro-climate. Regions having similar climatic features are grouped under one climatic zone. An analysis of the climate of a particular region can help in assessing the seasons or periods during which a person may experience comfortable or uncomfortable conditions. It further helps in identifying the climatic elements, as well as their severity, that cause discomfort. This information helps a designer to build a house that filters out adverse climatic effects, while simultaneously allowing those that are beneficial(Papakostas \& Kyriakis, 2005).

In India, (Bansal \& Minke, 1988) had carried out detailed studies and reported that India can be divided into six climatic zones, namely, hot and dry, warm and humid, moderate, cold and cloudy, cold and sunny, and composite. The criteria of classification are described in Table 1. A place is assigned to one of the first five climatic zones only when the defined conditions prevail there for more than six months. In cases where none of the defined categories can be identified for six months or longer, the climatic zone is marked as composite.

According to National Building Codes, 2005 (NBC) the country has been divided into five major climatic zones. It is seen that this modification in classification is not very different from the earlier one except that the cold and cloudy, and cold and sunny climates have been grouped as cold climate. The moderate climate is renamed as temperate climate(Bureau of India Standards, 2005). Figure 1 presents the different climate zones on the map of India.

Table 1: Bansal \& Minke climate zone criteria

\begin{tabular}{|c|c|c|c|c|}
\hline Climate Zones & $\begin{array}{c}\text { Mean Monthly } \\
\text { Temperature }\left({ }^{\circ} \mathrm{C}\right)\end{array}$ & Relative Humidity (\%) & Precipitation (mm) & $\begin{array}{c}\text { Number of Clear } \\
\text { Days }\end{array}$ \\
\hline Hot \& Dry & $>30$ & $<55$ & $<5$ & $>20$ \\
\hline Warm \& Humid & $>30$ & $>55$ & $>5$ & $<20$ \\
\hline Moderate & $25-30$ & $<75$ & $>5$ & $>20$ \\
\hline Cold \& Cloudy & $<25$ & $>55$ & $<5$ & $>20$ \\
\hline Cold \& Sunny & $<25$ & $<55$ & $>5$ \\
\hline Composite & \multicolumn{2}{|c|}{ When Six month or more do not fall within any of the above categories } \\
\hline
\end{tabular}




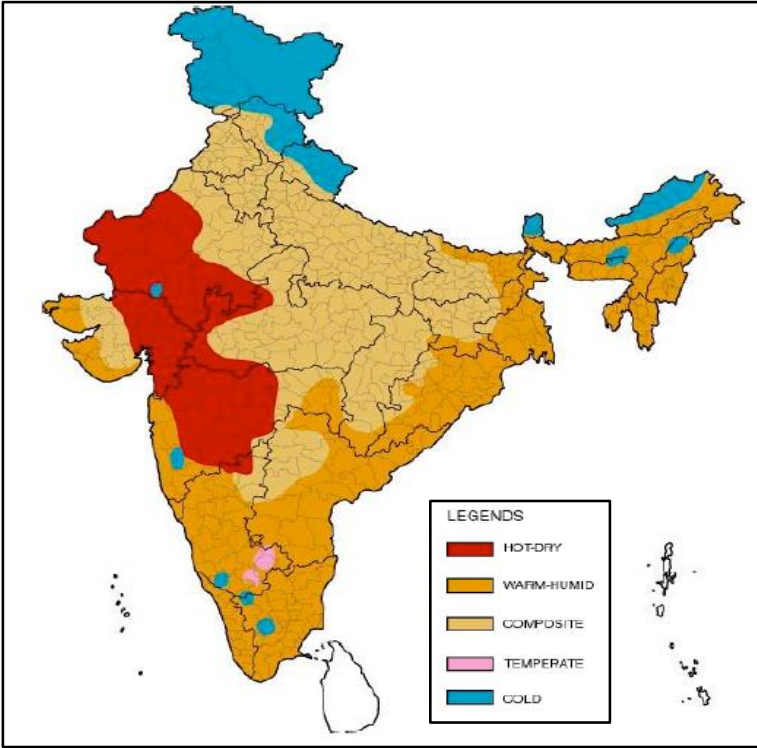

Figure 1: NBC climatic region(Bureau of Indian Standard, 2016)

However, due to the vast size of India and its complex geography, the climate in this part of the world have significant spatial and temporal variation. Dash et.al. analysed the effect of climate change on India in the 20th century and found that the mean temperature during premonsoon and monsoon months have increased and the rainfall pattern indicates an increment in winter and premonsoon months, for example, March and April (Dash, Jenamani, Kalsi, \& Panda, 2007). Additionally, these climate classification systems are focused on outdoor conditions, which do not include building and occupant comfort parameters such as indoor temperature, relative humidity in the categorization of climate zones. Therefore, there is a possibility of having more than five climate zones in India which make it necessary to revisit the climate classification for Indian cities.

Briggs et al. proposed a new climate classification in 2003 which was later included in ASHRAE standard 169 (Briggs, Lucas, \& Taylor, 2003a). This climate classification is based on two parameters: air temperature and precipitation. The CDD and HDD define the air temperature. The degree-day is essentially the summation of temperature differences over time, and hence they capture both extremity and duration of outdoor temperatures. The temperature difference is between a base (reference) temperature and the outdoor air temperature. This climate classification system uses cooling criteria $\left(\mathrm{CDD} 10^{\circ} \mathrm{C}\right)$ for the cooling dominated climates and heating criteria (HDD $18^{\circ} \mathrm{C}$ ) for heatingdominated climates for zone division.

The International Energy Agency defined six climatic zones based on heating and cooling degree days using the base temperature for both degree day definitions as $18^{\circ} \mathrm{C}$.

The degree-day accounts for fluctuation in the outdoor temperature and eliminates those periods when heating or cooling systems do not need to operate for a day. Additionally, they can capture the extreme conditions in a month which cannot be captured by the monthly mean temperature method.

Several researchers used a clustering method for climate classification. Regionalization of the conterminous United States was done using hierarchical cluster analysis on temperature and precipitation data (Fovell \& Fovell, 1993). Researchers used cluster analysis for climate classification such as for select a set of cities for use in analysing the nation's building stock (Andersson, Carroll, \& Martin, 1985); ASHRAE/IES Standard 90.1-1989 specified climate zones for building envelope requirements; a set of 16 climatic groups used in development of Standard 90.1-1999 (Briggs, Lucas, \& Taylor, 2003b).

This paper presents a revision of climate zones of India using a hierarchical clustering method using the climate indices of CDD, HDD and relative humidity.

\section{Methodology}

The principal tool used in developing climate zone classification is a statistical procedure called "hierarchical cluster analysis." Hierarchical cluster analysis uses a distance metric that represents the degree of similarity or dissimilarity between observations (e.g., climate sites) in a data set. In hierarchical clustering, the data is not partitioned into a particular cluster in a single step. Instead, a series of partitions takes place, which may run from a single cluster containing all objects to $\mathrm{n}$ clusters that each contain a single object. Hierarchical Clustering is subdivided into agglomerative methods, which proceed by a series of fusions of the $\mathrm{n}$ objects into groups, and divisive methods, which separate $\mathrm{n}$ objects successively into finer groupings. Figure 2 presents the process of agglomerative and divisive hierarchical clustering methods. Agglomerative techniques are more commonly used. Hierarchical clustering may be represented by a two-dimensional diagram known as a dendrogram, which illustrates the fusions or divisions made at each successive stage of analysis. Following is an example of a dendrogram ("Hierarchical Clustering | solver," n.d.).

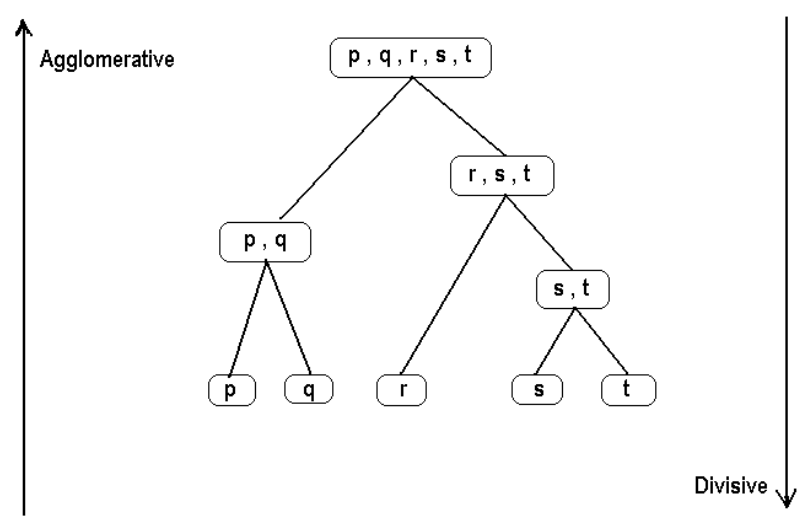

Figure 2: Hierarchical clustering methods ("Hierarchical Clustering | solver," n.d.)

An agglomerative hierarchical clustering procedure produces a series of partitions of the data. The first stage consists of all single object clusters. At each particular 
stage, the method joins together the two clusters that are closest together (most similar) called "distance matrix." Differences between results arise due to different ways of defining distance (or similarity) between clusters.

For the distance metric, any number of different climate indices (or clustering variables), such as heating and cooling degree-days, or average relative humidity can be used. Clusters are formed by calculating the distances between all possible pairs of observations in the data set, joining the two closest observations into a cluster, calculating values representing the centroid of the resulting cluster, and repeating this process until only a single cluster remains. The result of cluster analysis is a hierarchical (tree-like) arrangement of the observations into progressively nested set of subclusters. "Cutting" the nested cluster tree at a selected level results in a set of clusters that show the best way to group n observations such that each cluster is relatively homogeneous in terms of the initial clustering variables.

Critical decisions in using cluster analysis involve choosing the clustering variables and determining how to normalize and weight those variables (Briggs et al., 2003b).

The climate indices used in hierarchical clustering are cooling degree days, heating degree days, and annual average relative humidity. The $\mathrm{z}$-square normalization technique has used to normalize the variables.

According to the ASHRAE handbook of fundamentals, the daily degree-days can be calculated as the difference between the daily mean temperature $\left(\mathrm{T}_{\mathrm{d}}\right)$ and base temperature ( $\left.\mathrm{T}_{\text {base }}\right)($ ASHRAE, 2009). Daily heating degree-days and daily cooling degree-days are estimated by using equation (1) and (2) respectively.

$$
\begin{aligned}
& H D D_{d}=\left(T_{\text {base }}-\frac{T_{\text {max }}+T_{\text {min }}}{2}\right)^{+} \\
& C D D_{d}=\left(\frac{T_{\text {max }}+T_{\text {min }}}{2}-T_{\text {base }}\right)^{+}
\end{aligned}
$$

Where,

$\mathrm{T}_{\max }$ is daily maximum temperature and;

$\mathrm{T}_{\min }$ is daily minimum temperature.

The estimated base temperature used for cooling and heating degree day calculation is $18^{\circ} \mathrm{C}$ for India (Bhatnagar, Mathur, \& Garg, 2018).

Annual average relative humidity has been calculated using equation (3) and (4).

$R H_{M}=\operatorname{Avg}\left(R H_{1}: R H_{n}\right)$

$R H_{A}=\operatorname{Avg}\left(R H_{\text {Jan }}: R H_{\text {Dec }}\right)$

Where

RH: Relative humidity

M: Monthly (January, February,.... December)

$\mathrm{n}$ : total number of hours in a month

A: Annual

\section{Results and discussion}

The hierarchical agglomerative cluster technique has been applied on calculated CDD, HDD and annual mean relative humidity of 60 Indian cities. The weather data including dry-bulb temperature used for CDD and HDD; and hourly relative humidity has been derived from weather data developed by the Indian Society of Heating Refrigerating and Air-conditioning Engineers (ISHRAE). Figure 3 presents the CDD and HDD distribution of 60 Indian cities. From the figure, it is clear that the majority of Indian locations are under 500 HDD and more than 2000 CDD which indicates that India is a cooling dominated country.

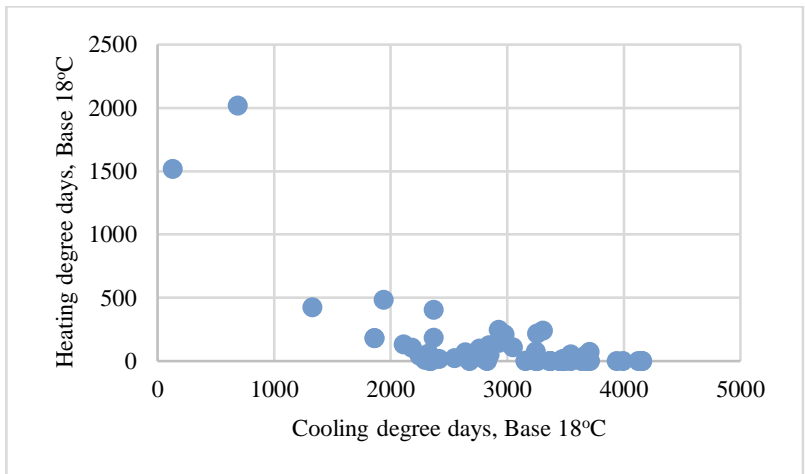

Figure 3: Distribution of cooling and heating degree days for 60 cities of India

Figure 4 plots CDD with respect to an annual mean relative humidity for different locations in India. The plot shows that the majority of the locations have more than $60 \%$ mean relative humidity. Even for locations where lowest CDD is less than 1,000 , the mean relative humidity exceeds $70 \%$.

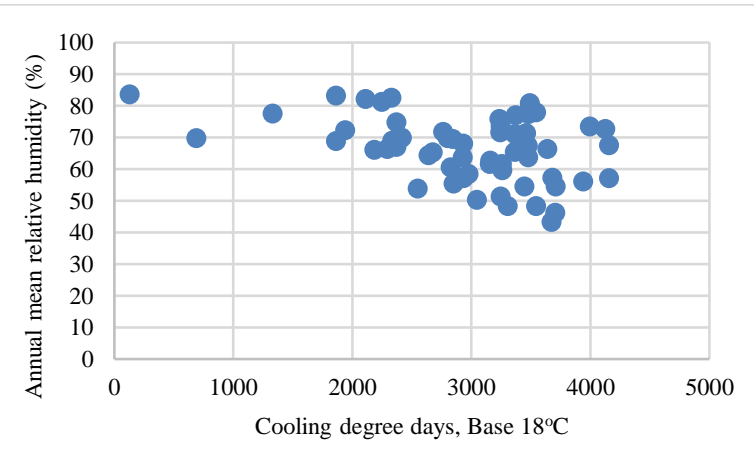

Figure 4: Distribution of cooling degree day and annual mean relative humidity of 60 cities of India

Figure 5 shows the results of hierarchical clustering of 60 cities into 8 groups. These 8 groups are considered as different climate zones. Table 2 shows cities with different locations. Three cities- Imphal, Shillong and Srinagar are from distinct clusters and are identified as the only city for their respective climate zone. 


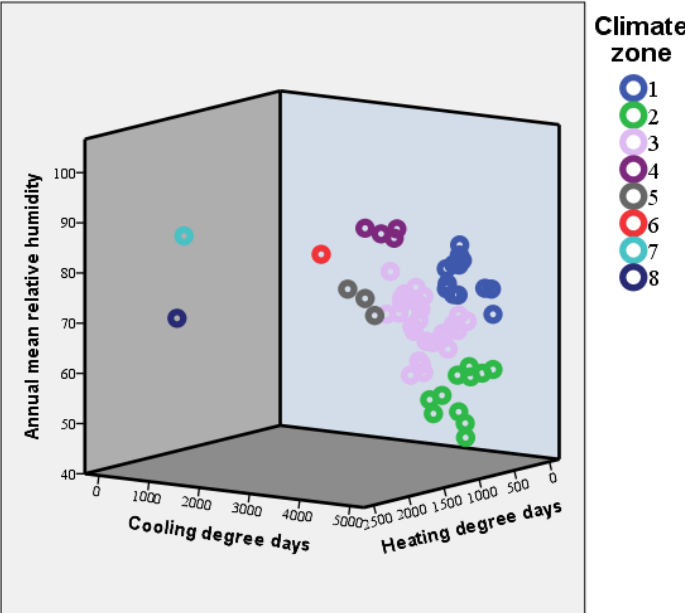

Figure 5: Clustering of 60 cities in 8 groups for CDD, $H D D$ and annual mean relative humidity

Table 2: Cities clustered in different groups using Hierarchical clustering

\begin{tabular}{|l|l|l|l|}
\hline Cities & CZ & Cities & CZ \\
\hline Bhubaneshwar & 1 & Hisar & 3 \\
\hline Chennai & 1 & Hyderabad & 3 \\
\hline Bhagalpur & 1 & Allahabad & 3 \\
\hline Mangalore & 1 & Gorakhpur & 3 \\
\hline Vishakhapatnam & 1 & Gwalior & 3 \\
\hline Kolkata & 1 & Indore & 3 \\
\hline Mumbai & 1 & Jabalpur & 3 \\
\hline Nellore & 1 & Jagdalpur & 3 \\
\hline Panjim & 1 & Jamnagar & 3 \\
\hline Ratnagiri & 1 & Patna & 3 \\
\hline Thiruvananthapuram & 1 & Pune & 3 \\
\hline Tiruchirappalli & 1 & Raipur & 3 \\
\hline Veraval & 1 & Ramagundam & 3 \\
\hline Ahmedabad & 2 & Ranchi & 3 \\
\hline Akola & 2 & Raxaul & 3 \\
\hline Barmer & 2 & Surat & 3 \\
\hline Bikaner & 2 & Lucknow & 3 \\
\hline Kota & 2 & Nagpur & 3 \\
\hline Jaipur & 2 & New Delhi & 3 \\
\hline Jaisalmer & 2 & Varanasi & 3 \\
\hline Jodhpur & 2 & Dibrugarh & 4 \\
\hline Kurnool & 2 & Guwahati & 4 \\
\hline Rajkot & 2 & Jorhat & 4 \\
\hline Solapur & 3 & Tezpur & 4 \\
\hline Aurangabad & 3 & Amritsar & 5 \\
\hline Belgaum & Dehradun & 5 \\
\hline Bengaluru & Saharanpur & 5 \\
\hline Bhopal & Imphal & 6 \\
\hline Bhuj & Shillong & 7 \\
\hline Chitradurga & Srinagar & 8 \\
\hline CZ: Climate Zone & \\
\hline
\end{tabular}

* CZ: Climate Zone

Table 3 presents a categorization of climatic indices (CDD, HDD and RH) based on clustering. The climate zone 1 and 2 have a hotter climate as the range of CDD are from 3000 to 4200 . However, the variation is due to mean relative humidity. The climate zone 1 has higher mean relative humidity compared to climate zone 2 . The climate zone 4 and 5 have similar CDD ranges, while, the HDD and relative humidity shows variation. The climate zone 3 has overlapping in CDD and HDD values with other climate zones, but the relative humidity has a different range. The climate zones 6,7, and 8 have distinct values of CDD and HDD with respect to other climate zones.

Table 3: Climate zone classification for India

\begin{tabular}{|c|c|c|c|c|c|c|}
\hline $\begin{array}{c}\text { Climate } \\
\text { Zones }\end{array}$ & $\begin{array}{c}\text { CDD } \\
\text { Min }\end{array}$ & $\begin{array}{c}\text { CDD } \\
\text { Max }\end{array}$ & $\begin{array}{c}\text { HDD } \\
\text { Min }\end{array}$ & $\begin{array}{c}\text { HDD } \\
\text { Max }\end{array}$ & $\begin{array}{c}\text { RH } \\
\text { Min }\end{array}$ & $\begin{array}{c}\text { RH } \\
\text { Max }\end{array}$ \\
\hline 1 & 3231 & 4154 & 0 & 8 & 68 & 81 \\
\hline 2 & 3046 & 4153 & 0 & 240 & 43 & 57 \\
\hline 3 & 2181 & 3638 & 0 & 248 & 54 & 76 \\
\hline 4 & 1861 & 2325 & 43 & 182 & 81 & 83 \\
\hline 5 & 1861 & 2369 & 182 & 484 & 67 & 73 \\
\hline 6 & 1328 & - & 427 & - & 78 & - \\
\hline 7 & 128 & - & 1518 & - & 84 & - \\
\hline 8 & 688 & - & 2018 & - & 70 & - \\
\hline
\end{tabular}

\section{Conclusion}

According to the National Building Code of India, the country has been divided into five major climatic zones based on mean monthly temperature, and mean monthly relative humidity. However, NBC climate zone classification focused on only outdoor conditions, which does not include building and occupant comfort parameters such as indoor temperature, relative humidity in the categorization of climate zones. Internationally, the CDD and HDD have been commonly used as indicators of cooling and heating load occurring due to the outdoor temperature. Another study estimated $18^{\circ} \mathrm{C}$ as the new base temperature of cooling and heating for India which has been used to calculate CDD and HDD for 60 Indian locations. The HDD and CDD with new base temperature have been used for sensible component and the annual mean relative humidity for the latent component of the climate.

From the analysis, India has been classified into 8 climate zones using $\mathrm{CDD}, \mathrm{HDD}$ and annual mean relative humidity.

The climate zones based on CDD, HDD and RH are more appropriate for the analysis on buildings because it unite outdoor conditions with the indoor conditions of the building. This provides building designers to analyse energy conservation measures related to climate that also provide comfort to occupants and save energy.

\section{References}

Andersson, B., Carroll, W. L., \& Martin, M. . (1985). Aggregation of U.S. Population Centers into Climate Regions. ASHRAE Transactions 91, 2, 109-121. from 
https://cloudfront.escholarship.org/dist/prd/content /qt9hw07906/qt9hw07906.pdf

ASHRAE. (2009). 2009 ASHRAE HandbookFundamentals. ASHRAE.

Bansal, N. K., \& Minke, G. (1988). Climatic zones and rural housing in India, (199004). https://doi.org/citeulike-article-id:10601847

Bhatnagar, M., Mathur, J., \& Garg, V. (2018). Determining base temperature for heating and cooling degree-days for India. Journal of Building Engineering, 18(January), 270-280. https://doi.org/10.1016/j.jobe.2018.03.020

Briggs, R. S., Lucas, R. G., \& Taylor, Z. T. (2003a). Climate Classification for Building Energy Codes and Standards : Part 2 - Zone Definitions, Maps, and Comparisons.

Briggs, R. S., Lucas, R. G., \& Taylor, Z. T. (2003b). Climate classification for building energy codes and standards: Part 1-development process. Transactions-American Society of Heating Refrigerating and Air Conditioning Engineers, 109(1), 109-121.

Bureau of India Standards. (2005). National Building Code of India (2005th ed.). Bureau of India Standards.

Bureau of Indian Standard. (2016). National Building Code of India 2016 part 1 (3rd ed., Vol. 2). India: Bureau of Indian Standard.

Dash, S. K., Jenamani, R. K., Kalsi, S. R., \& Panda, S. K. (2007). Some evidence of climate change in twentieth-century India. Climatic Change, 85(3-4), 299-321. https://doi.org/10.1007/s10584-0079305-9

Fovell, R. G., \& Fovell, M. Y. C. (1993). Climate Zones of the conterminous United stares defined using cluster analysis.pdf. American Meteorological Society, 6, 2103-2135.

Hierarchical Clustering | solver. (n.d.). Retrieved February 5, 2019, from https://www.solver.com/xlminer/help/hierarchicalclustering-intro

Papakostas, K., \& Kyriakis, N. (2005). Heating and cooling degree-hours for Athens and Thessaloniki, Greece. Renewable Energy, 30(12), 1873-1880. https://doi.org/10.1016/j.renene.2004.12.002 